\title{
Observatório de Inovação do Turismo
}

\section{Inter-relação e capitais mobilizados por diferentes tipos de empreen- dedores no processo de reconversão de funções econômicas de cida- des: um estudo de caso em Paraty (RJ)}

Interaction and capital mobilized by different types of entrepreneurs in the process of conversion of economic functions of cities: a case study in Paraty (RJ)

Fátima Bayma de Oliveira ${ }^{1}$

Anderson de Souza Sant'Anna² Antonio Moreira de Carvalho Neto ${ }^{3}$ Daniela Martins Diniz ${ }^{4}$ João Evangelista Dias Monteiro ${ }^{5}$

\section{Resumo}

O objetivo deste artigo é apresentar os resultados de uma pesquisa cujo propósito foi o de identificar diferentes tipos de empreendedores no processo de reconversão de funções econômicas da cidade de Paraty (RJ) e analisar as características desses empreendedores, suas formas de atuação e as inter-relações que eles estabelecem neste processo. Como revisão teórica, utilizaram-se pesquisas sobre processos de reconversão de funções econômicas de cidades, sobre tipologias de empreendedor e sobre os estudos de Bourdieu (habitus, capital e

'Filiação Institucional: Fundação Getulio Vargas.Doutora em Educação, Professora titular da FVG nos cursos de doutorado, mestrado, especialização e graduação em Administração. E-mail: fbayma@fgv.br

${ }^{2}$ Filiação Institucional: Fundação Dom Cabral. Doutor em Administração pela Universidade Federal de Minas Gerais. Professor da Fundação Dom Cabral e do Programa de Pós-Graduação em Administração da Pontifícia Universidade Federal de Minas Gerais. Coordenador do Núcleo Vale de Desenvolvimento de Liderança da Fundação Dom Cabral. E-mail: anderson@fdc.org.br

${ }^{3}$ Coordenador do Programa de Pós-Graduação em Administração da PUC- Minas. Doutor em Administração pela UFMG (1999), com doutorado sanduíche no Instituto de Economia da UFRJ e no IUPERJ.

${ }^{4}$ Filiação Institucional: Fundação Dom Cabral. Mestre em Administração pela Pontifícia Universidade Católica de Minas Gerais, na linha de pesquisa de Estratégia e Inovação. Graduação em Administração. Colaboradora do Núcleo Vale de Desenvolvimento de Liderança da Fundação Dom Cabral. E-mail: danidiniz09@yahoo.com.br

${ }^{5}$ Filiação Institucional: Universidade Federal Fluminense. Doutor em Economia; professor adjunto de economia do turismo, do Departamento de Turismo, da Faculdade de Administração, Ciências Contábeis e Turismo. e-mail: joaoedm@ turismo.uff.br 
campo). Em termos metodológicos, a pesquisa pode ser caracterizada como um estudo qualitativo, com base no método de estudo de caso, com o uso de 23 entrevistas em profundidade e análise documental. Como resultado, foi possível observar a presença de empreendedores tradicionais, modernos e pós-modernos em Paraty, mobilizando capitais e estabelecendo conflitos e alianças no âmbito do processo de reconversão de funções econômicas da cidade.

Palavras-chave: : processo de reconversão de funções econômicas de cidades, tipos de empreendedor, empreendedores tradicionais, modernos e pós-modernos

\section{Abstract}

The aim of this paper is to discuss the results of a research whose purpose was to identify different types of entrepreneurs in the process of conversion of economic functions of the city of Paraty $(R J)$ and analyze the characteristics of these entrepreneurs, their ways of acting and the relationships they establish in this process. The review theoretical included research about the processes for the conversion of economic functions of cities, the types of entrepreneurial and studies of Bourdieu. We conducted a qualitative study, based on the method of case study, using 23 interviews and document analysis. As a result, we observed the presence of entrepreneurs traditional, modern and postmodern in Paraty, mobilizing capital and establishing alliances and conflicts within the process of conversion of the city.

Key words: process of conversion of economic functions of cities types of entrepreneur, entrepreneurs traditional, modern and post-modern.

\section{Introdução}

O aproveitamento do patrimônio cultural e natural de uma cidade como estratégia para o seu desenvolvimento socioeconômico constitui tema de estudo recente. Tal interesse acadêmico se deve à experiência de diversas cidades brasileiras que promoveram iniciativas de valorização de seu patrimônio arquitetônico e artístico, a partir da década de 1920. Com isso, tais localidades têm-se tornado atrativas do ponto de vista turístico, o que, por sua vez, tem contribuído para um processo de transformação e melhoria dos indicadores socioeconômicos. Tal processo foi denominado de diversas formas na literatura, porém se adotou, nesta pesquisa, o termo "reconversão de funções econômicas".

Nesse contexto, o turismo tem sido apontado como o impulsionador de muitos des- 
ses processos. Tal atividade econômica tem proporcionado às cidades melhoria no nível de emprego, renda, acesso à educação, entre outros benefícios.

Motivados a conhecer melhor esse fenômeno, diversos estudos vêm direcionando a atenção para aspectos não só relacionados com investimentos na infraestrutura física para o turismo, mas também com repercussões desse processo nas inter-relações entre os atores locais. Isso implica investigação da dinâmica do processo de transformação e da interação entre os indivíduos na cidade em estudo, bem como das formas de atuação desses atores. Mesmo porque a literatura existente pouco avançou para uma compreensão mais fidedigna desses fenômenos.

Entre os agentes locais que influenciam o processo de reconversão de uma cidade, é possível destacar o Poder Público, a comunidade, os empresários e as associações. Entretanto se constatou que os empreendedores se configuraram como atores centrais nas transformações vivenciadas por Paraty. Desse modo, a presente pesquisa deu ênfase aos empreendedores locais (donos de pousadas, restaurantes, lojas), sem desconsiderar, entretanto, outros atores que podem influenciar tal dinâmica.

Dado esse contexto, esta pesquisa tem como propósito central identificar diferentes tipos de empreendedores e analisar de que forma eles se inter-relacionam e mobilizam capitais no processo de reconversão de funções econômicas, baseado no turismo cultural, vivenciado pela cidade de Paraty (RJ). Assim, a problemática deste estudo pode ser assim delimitada: "Qual(is) (o)s tipo(s) e de que forma diferentes empreendedores se inter-relacionam e mobilizam capitais no processo de reconversão de funções econômicas, apoiado no turismo cultural, vivenciado pela cidade de Paraty?"

Nesse contexto, os objetivos específicos da pesquisa podem ser assim definidos: (i) caracterizar o processo de reconversão de funções econômicas de Paraty; (ii) identificar e caracterizar os tipos de empreendedores atuantes na cidade; (iii) analisar de que forma os empreendedores atuam e se inter-relacionam na dinâmica de reconversão.

Como referencial teórico utilizou-se pesquisas sobre o processo de requalificação de funções econômicas de cidades, baseado no turismo (BENTLEY, 2005). Além disso, adotaram-se os estudos de Bourdieu $(2010,1996,1990)$ para subsidiar a análise da articulação entre atores sociais na cidade de Paraty. Por fim, fez-se uma revisão da literatura sobre tipologias de empreendedor que abordou, sobretudo, o modelo proposto por Santanna, Nelson e Oliveira (2011).

Em termos metodológicos, empreendeu-se a pesquisa de campo de natureza qualitativa, com base no método de estudo de caso. Tal metodologia se mostrou apropriada, pois possibilitou a compreensão do fenômeno estudado em profundidade, considerando-se o contexto no qual ele ocorre (EISENHARDT, 1989; YIN, 2005). Com isso, foi possível contribuir 
para os estudos sobre tipologia de empreendedores, tendo em vista as lacunas existentes na literatura sobre o tema.

Quanto à unidade de pesquisa, o estudo ocorreu em Paraty, ponderando-se que a cidade vem vivenciando processos de reconversão de funções econômicas baseados no turismo cultural. Assim, trata-se de um caso representativo levando-se em conta os propósitos do estudo. Para a coleta de dados, utilizaram-se documentos históricos que contribuíram para a descrição do contexto de transformação de Paraty. Conduziram-se, também, duas visitas in loco à cidade e realizaram-se 23 entrevistas com empreendedores, representantes do Poder Público e indivíduos vinculados às associações e à comunidade.

No que tange à sua relevância, a pesquisa justifica-se, em termos teóricos, ao ampliar os estudos sobre processos de reconversão de funções econômicas de cidades, correlacionando-os aos tipos de empreendedores. Além disso, este estudo pode contribuir para aprimorar a compreensão acerca das tipologias de empreendedores, tendo em vista que, somente mais recentemente, as pesquisas sobre o tema têm chamado a atenção para as variações existentes entre eles.

Em termos práticos, o estudo justifica-se ao contribuir com subsídios para o desenvolvimento de políticas direcionadas a processos de reconversão de funções econômicas de cidades, bem como para o desenvolvimento de empreendedores neles envolvidos. Finalmente, não há dúvida quanto à importância de localidades que mobilizam recursos culturais e naturais como base de seus novos modelos de desenvolvimento, como é o caso de algumas cidades brasileiras, como Paraty e Tiradentes.

\section{Fundamentação teórica}

\subsection{NoÇÃO DE RECONVERSÃO DE FUNÇÕES ECONÔMICAS DE CIDADES}

Debates produzidos no meio acadêmico têm alertado para a importância de analisarem-se cidades submetidas a processos de requalificação de funções econômicas. Ao mesmo tempo, têm estimulado reflexões sobre as implicações dessas transformações nos arranjos locais e no potencial de desenvolvimento de certas localidades. Tal interesse acadêmico pode ter-se dado pela experiência de cidades brasileiras e internacionais com processos de revalorização do patrimônio arquitetônico, cultural e humano que contribuíram para uma melhoria de indicadores socioeconômicoslocais. Tais processos já assumiram diferentes nomenclaturas na literatura, tais como requalificação, reestruturação e reconversão de funções econômicas - termo adotado neste artigo - embora seja tema de estudo recente. 
Um ponto comum entre essas diferentes expressões é que elas se baseiam em tendências contemporâneas de planejamento estratégico de cidades em que se pressupõe a cidade como um negócio e busca-se torná-la competitiva por meio de investimentos em comunicação, promoção e infraestrutura local (HARVEY, 1996; BORJA; CASTELLS, 1997). Assim, acaba-se por enfraquecer o planejamento urbano como papel exclusivo do estado, fortalecendo perspectivas do planejamento estratégico conduzido por empreendimentos privados (LUCHIARI, 2005).

O conceito de reconversão também se encontra associado às noções de reestruturação socioeconômica e à reformulação institucional das atividades econômicas locais (BENTLEY, 2005). A primeira perspectiva centra-se na melhoria de indicadores socioeconômicos locais, e a segunda enfatiza a valorização de projetos que levem em conta o patrimônio histórico-cultural de uma localidade e a promoção de um sustentável desenvolvimento social.

No âmbito dessas transformações, diversas cidades vêm adotando estratégias para se fortalecerem como polos de atração de capitais. Entre os fatores que motivaram tais cidades a adotar tais estratégias para seus projetos de transformação urbana, destacam-se: (i) sensação de crise pela tomada de consciência da necessidade de processo de requalificação; (ii) articulação entre atores públicos e privados e configuração de lideranças; (iii) vontade dos cidadãos para que a cidade melhorasse (FISCHER, 1996).

Nesse contexto, o turismo tem sido apontado como um dos principais responsáveis pela reestruturação e melhoria de indicadores de muitas cidades. Com isso, diversos estudos na área vêm direcionando a atenção para aspectos não só relacionados com os investimentos na infraestrutura para o turista, mas também com as implicações sociais dessa atividade econômica, tendo em vista que ela influencia a interação entre os atores locais (BALASTRE$\mathrm{RI}, 2006)$.

O crescimento e o desenvolvimento do turismo, entretanto, tende a causar impactos positivos na região, como a geração de emprego, renda, inclusão social e, negativos como a degradação ambiental e problemas sociais. A expansão dessa atividade influencia também os arranjos sociais estabelecidos entre as pessoas que têm uma ligação com a cidade, sejam aquelas nascidas no local, as que foram morar tardiamente ou os turistas. Assim, tais atores utilizam mecanismos para se apropriar de forma concreta ou abstrata de porções do espaço. Dessa maneira, os territórios comportam-se como meios e produtos das relações de poder produzidas para e pelo turismo (RAFFESTIN, 1993).

Nesse sentido, a cidade deve ser entendida não somente como território que concentra infraestrutura física e atividades econômicas, mas também como um espaço onde atores sociais, com interesses contraditórios e/ou convergentes, se relacionam por meio de alianças ou conflitos. Portanto, considerando-se que diversos agentes se articulam no processo de 
requalificação econômica de cidades e, ainda, tendo em vista um dos objetivos deste artigo - analisar como diferentes tipos de empreendedores se relacionam e mobilizam capitais - foi incorporado à fundamentação teórica os construtos desenvolvidos por Bourdieu (2010; 2009a; 2009b; 1996; 1990), discutidos na seção seguinte.

\subsection{INTER-RELAÇÃO ENTRE DIFERENTES TIPOS DE EMPREENDEDORES: UMA ANÁLISE COM BASE NA PERSPECTIVA DE BORDIEU E NOS ESTUDOS SOBRE TIPOLOGIAS DE EMPREENDEDORES}

Para compreender articulações entre diferentes atores sociais, no caso do presente artigo com foco nos empreendedores, analisou-se a obra de Bourdieu (habitus, campo e capital). Essa linha de pesquisa pode contribuir para um melhor entendimento sobre a maneira com que agentes disputam, se distinguem e estabelecem alianças para a posse dos capitais distribuídos num espaço social.

Uma das principais ideias de Bourdieu é a de que atores sociais, dotados de habitus (atributos) similares ou distintos e de capitais (econômicos, culturais e simbólicos) distribuídos de modo desigual, se inter-relacionam no interior de um espaço social onde se desenrolam conflitos e alianças em busca da manutenção ou transformação do estado vigente de forças. Nesse trecho revelam-se, portanto, três conceitos do autor: o habitus, o campo e o capital simbólico (BOURDIEU, 2010, 2009a, 2009b, 1990).

Iniciando pelo habitus, Bourdieu (1990), define-o como um sistema de disposições e princípios duráveis (mas transponíveis) que pode funcionar como "estruturas estruturantes", isto é, como esquemas geradores e organizadores de ações coletivas e individuais. O habitus pressupõe, portanto, um conjunto de princípios de visão e de gostos que orientam a escolha dos indivíduos e que os direciona a agir de determinadas maneiras. Embora o habitus forneça ao indivíduo um sentido para seu comportamento, ele não implica uma imposição a regras (BOURDIEU, 1990; BOURDIEU e ORTIZ, 1994).

Atores sociais dotados de mesmo habitus tendem a agir de forma "harmoniosa", tornando as práticas dos indivíduos "sensatas", sem quaisquer razões explícitas para isso. Por outro lado, indivíduos com habitus distintos tendem a agir de forma diferente e, por isso, Bourdieu considera o habitus um princípio diferenciador (BOURDIEU, 1996, 2010).

O campo, por sua vez, é um espaço dinâmico constituído de posições distintas ocupadas por atores sociais e determinadas pelo volume de capital detido por eles. É conceituado também como ambiente onde se desenrolam lutas e alianças entre agentes em busca da manutenção ou transformação do estado vigente de forças (BOURDIEU, 1990; PECI, 2003; BOURDIEU e ORTIZ, 1994).

Como a posse de capital tende a ser desigual, existem, no interior do campo, diversos 
grupos caracterizados por estilos de vida diferentes. De tal modo que o campo vive em conflito onde os grupos dominantes buscam manter seus privilégios e os demais tentam alterar a distribuição de capital vigente. Não obstante, é possível observar também a formação de alianças entre atores em busca de espaço e poder (MISOCZKY, 2003).

Por fim, o capital é a principal forma de poder e elemento de distinção no interior de um campo, sendo, simultaneamente, instrumento e objeto de disputa. Bourdieu (1990) pressupõe a existência de três tipos de capital (econômico, cultural e simbólico), superando abordagens tradicionais que consideram somente a perspectiva econômica (BONNEWITZ, 2005; BOURDIEU, 1990).

O conceito de capital econômico de Bourdieu é similar à definição de Marx: recursos associados aos fatores de produção (terra, fábrica e trabalho) e aos ativos econômicos, como os bens materiais. O capital cultural, por sua vez, corresponde ao conjunto de conhecimentos e qualificações intelectuais transmitidas pela família e pelas instituições escolares durante a vida do indivíduo. Por fim, o capital simbólico está relacionado com a acumulação de prestígio e reconhecimento social pelo indivíduo ou grupo que preservam sob seus domínios os recursos considerados essenciais num determinado campo (TEIXEIRA, 2010; THIRY-CHERQUES, 2006).

As diferenças existentes no interior de um campo, sobretudo em termos de capital, possibilitam a construção de "classes sociais teóricas". Não são classes concretas, pois o que há é um espaço de diferenças, no qual as classes existem em estado virtual. Assim, cada "classe" de posições está associada a uma cultura específica (ou a um habitus). Ao optarem por um estilo de vida, os indivíduos acabam se autoclassificando em relação a uma classe social (BOURDIEU, 1990).

Além dos conceitos de Bourdieu, aborda-se, também, nesta seção, um arcabouço teórico sobre tipologias de empreendedores. Entretanto se constatou que a literatura existente carece de uma variedade de tipos de empreendedores, tendo em vista que só recentemente surgiram pesquisas que propõem tipologias com mais de três categorias (SMITH, 1967; COOPER et al., 1997; SANTANNA; NELSON; OLIVEIRA, 2011).

A tipologia mais antiga é a de Smith, desenvolvida na década de 1960, cuja influência perdura até hoje. Smith (1967) identificou dois tipos de empreendedores: os artesãos e os oportunistas. O primeiro caracteriza-se por ser filho de operários e ter treinamento técnico. Trata-se de profissional dedicado à excelência no serviço que desempenha e tenta evitar influência de gerentes e sindicatos no exercício de seu ofício. Preza serviços de qualidade e empregados sérios e não se importa com o crescimento. Já o oportunista normalmente tem curso superior completo em áreas como a administração, mas raramente em áreas técnicas, como a engenharia. É comum que tenha experiência como gestor antes da abertura do próprio negócio. Vale salientar ainda que o indivíduo com esse perfil busca o crescimento da 
empresa e lucros crescentes.

Décadas subsequentes trouxeram novas tipologias, mas parece ter persistido a tensão entre crescimento e lucro, de um lado, e foco em excelência na produção, de outro. Independentemente dos esforços em criar tipologias, vários estudiosos redescobriram o conceito de bricolage que pode ser compreendido como dar um jeito ou improvisar com o que se tem à mão (GARUD; KARNOE, 2003). Empreendedores que praticam bricolage parecem criar algo do nada, com base na combinação de materiais usados, métodos de trabalho informais e criatividade para a solução de problemas (BAKER; NELSON, 2005; LEVI-STRAUSS, 1966).

Com o avanço dos estudos nessa área, foi-se constatando que os empreendedores apresentam variações entre si e que essas diferenças têm implicações conceituais e práticas. Assim, em estudos recentes, retoma-se a atenção para a variação entre os empreendedores. Santanna, Nelson e Oliveira (2011), por exemplo, realizaram uma pesquisa na cidade de Tiradentes (MG) e identificaram tipos de empreendedores no local. Com base em análise exaustiva dos dados empíricos, os autores propuseram um modelo de tipologias de empreendedores: empreendedores tradicionais (nativos e aristocratas), empreendedores modernos (conscientes e utilitaristas) e empreendedores pós-modernos (vanguardistas e camaleões) (SANTANNA; NELSON; OLIVEIRA, 2011).

Os empreendedores tradicionais, como o nome revela, têm como principal capital a "tradição", porém podem distinguir-se na forma como manifestam tal noção, gerando duas categorias no âmbito dos tradicionais: os nativos e os aristocratas. Os empreendedores nativos valorizam mais a "linhagem familiar" e o "nome de família", enquanto os aristocratas dão mais ênfase à "linhagem cultural", apreciando aspectos como "nível cultural" e "erudição" (SANTANNA; NELSON; OLIVEIRA, 2011).

Os empreendedores nativos são, geralmente, pequenos comerciantes e empreendedores individuais - marceneiros, doceiras e outros profissionais de ofício - nascidos na região, os quais, em sua maioria, já mantinham negócios na cidade antes da expansão do turismo. Os aristocratas, por sua vez, são pioneiros na abertura de empreendimentos direcionados ao turismo cultural, ou seja, adequados a um público que aprecia produtos/serviços culturais e artísticos. Um traço distintivo desse grupo, além de seu background cultural, é a estreita ligação de seus empreendimentos a projetos pessoais, que são apresentados não como negócios, mas como projetos de vida. Além disso, ao contrário dos nativos, os aristocratas tentam diferenciar-se pelo fato de terem nascido em outros locais ou, apesar de nascidos na cidade, terem vivenciado experiências em outros países/cidades (SANTANNA; NELSON; OLIVEIRA, 2011).

Os empreendedores tradicionais disputam espaço com outro grupo de empreendedores: os modernos. Esse grupo, por sua vez, pode ser classificado em duas categorias (os 
conscientes e os utilitaristas), embora se assemelhem no que se refere à valorização da qualificação formal e de valores que extrapolem o aspecto da tradição (SANTANNA; NELSON; OLIVEIRA, 2011).

Os empreendedores conscientes são, geralmente, profissionais liberais ou ex-executivos de grandes empresas que decidiram sair dos centros urbanos para morar em cidades menores, vislumbrando melhor qualidade de vida, e abrir um negócio próprio. Como atributos dos empreendedores conscientes, além da valorização da "instrução em nível superior, especialmente em gestão", merecem destaque os discursos e as posturas associados a conceitos de responsabilidade social empresarial. Nessa direção, tendem a demonstrar maior preocupação com as questões que afetam toda a cidade (SANTANNA; NELSON; OLIVEIRA, 2011).

Por outro lado, os empreendedores utilitaristas, embora também valorizem a qualificação formal, são associados a expressões, como a "busca frenética por lucro" e pela adoção da "lógica de gestão de curto prazo". Nesses termos, tendem a preocupar-se mais com a gestão e o desempenho do negócio do que com as questões sociais, econômicas e políticas da cidade. Então, embora os empreendedores utilitaristas e conscientes tenham em comum a valorização da qualificação formal, é provável que se diferenciem na forma como realizam a gestão de seus negócios e como lidam com as questões coletivas da cidade (SANTANNA; NELSON; OLIVEIRA, 2011).

Finalmente, os empreendedores pós-modernos - os quais divergem dos tradicionais por serem flexíveis e inconstantes - parecem distinguir-se em duas subcategorias, as quais se denominaram empreendedores vanguardistas e camaleões. Os empreendedores vanguardistas são constituídos por proprietários de ateliers de arte, pintores e demais artistas, que se caracterizam por atributos, tais como "criação", "novo", "independência", "negação da tradição", "contestação", "desprendimento" e por "estilos de vida particulares" (SANTANNA; NELSON; OLIVEIRA, 2011).

Já os empreendedores camaleões compõem-se de trabalhadores oriundos de grandes centros e também de cidadãos da cidade que perceberam, no processo de transformação econômica, oportunidades de "fazerem a vida". Com recursos financeiros escassos, comparativamente aos empreendedores modernos e aristocratas, constituem seus negócios na base da improvisação e da imitação. Assim, propõem-se a ofertar seus produtos e serviços a turistas sem condições financeiras de frequentar ambientes mais refinados. Geralmente estão inseridos na economia informal e na irregularidade (SANTANNA; NELSON; OLIVEIRA, 2011).

O quadro abaixo apresenta uma síntese das tipologias de empreendedores propostas por Santanna, Nelson e Oliveira (2011). 


\section{Quadro 1: Atributos de distinção por tipo de empreendedor}

\begin{tabular}{|c|c|c|}
\hline Categorias & Subcategorias & Atributos Distintivos \\
\hline \multirow[t]{2}{*}{$\begin{array}{l}\text { Empreendedores } \\
\text { tradicionais }\end{array}$} & Empreendedores nativos & $\begin{array}{l}\text { Provincianismo, família, simplicidade, rusticidade, } \\
\text { timidez, "falta de ambição", conservadorismo, " } \\
\text { estilo de vida popular". }\end{array}$ \\
\hline & Empreendedores aristocratas & $\begin{array}{l}\text { Cultura, refinamento, bom gosto, estilo, memória } \\
\text { histórica, "respeito ao local e à natureza", "empre- } \\
\text { endimento como projeto de vida". }\end{array}$ \\
\hline $\begin{array}{l}\text { Empreendedores } \\
\text { modernos }\end{array}$ & Empreendedores utilitaristas & $\begin{array}{l}\text { Entretenimento, curto prazo, lucro imediato, indi- } \\
\text { vidualismo, ambição, resultado financeiro, cresci- } \\
\text { mento, aparência. }\end{array}$ \\
\hline
\end{tabular}

Empreendedores conscientes Qualificação, certificação, profissionalismo, modernidade, qualidade de vida, responsabilidade social, desenvolvimento sustentável.
Empreendedores
Empreendedores camaleões
Improvisação, imitação, informalidade, cópia, pós-modernos jeitinho brasileiro", senso de oportunidade, aven- tura, risco, flexibilidade, adaptabilidade.
Empreendedores vanguardistas
Arte, criação, originalidade, sensibilidade, au- tonomia, "negação da tradição", contestação, desprendimento, "estilo de vida particular".

Fonte: Adaptado de Santanna, Nelson e Oliveira (2011).

\section{Metodologia}

Considerando-se os propósitos desta investigação, optou-se pela realização de pesquisa de natureza qualitativa com o uso do método de estudo de casos (GREENWOOD, 1973; EISENHARDT, 1989; YIN, 2005). Tal metodologia consiste na análise exaustiva de um ou de poucos objetos empíricos, sejam eles situações, pessoas ou organizações, circunstâncias em que se encontram e natureza dos fenômenos que os compõem. É indicado quando o fenômeno em estudo é complexo, contemporâneo e insere-se num contexto real, como é o caso da 
presente pesquisa que investigou "tipos de empreendedores em processos de reconversão de funções econômicas de cidades". Com base no estudo de caso, foi possível obter uma análise profunda e holística do fenômeno pesquisado (GREENWOOD, 1973; EISENHARDT, 1989).

A seleção do caso em pesquisa qualitativa é uma decisão importante, pois pode impactar a relevância dos resultados do estudo. Portanto, essa escolha não deve ser aleatória, mas intencional, orientada para a riqueza com que o fenômeno se apresenta (EISENHARDT, 1989; YIN, 2005). Com base nessas premissas, optou-se pela realização da pesquisa empírica na cidade de Paraty (RJ) por sua representatividade como caso exemplar de processo de reconversão de função econômica. Vale salientar que se fez apenas um único caso, tendo em vista que é considerado "crítico" para a compreensão do fenômeno em estudo (YIN, 2005).

Em relação aos instrumentos de coleta de dados, utilizaram-se entrevistas em profundidade, análise documental e observação direta (EISENHARDT, 1989; SOY, 1997; YIN, 2005). Os sujeitos entrevistados foram empreendedores locais (donos de pousadas, restaurantes, lojas), representantes do Poder Público e indivíduos vinculados às associações e à comunidade. Realizaram-se duas visitas in loco a Paraty e 23 entrevistas com os sujeitos da pesquisa. O roteiro incluiu questões sobre a trajetória pessoal do respondente, sua visão acerca do processo de requalificação da cidade, os principais agentes envolvidos, suas características e formas de atuação. As entrevistas totalizaram mais de trinta horas, gerando mais de trezentas páginas de transcrição. A consulta a documentos históricos e bibliográficos, por sua vez, foi fundamental para a descrição da evolução histórica e dos processos de reconversão de funções econômicas de Paraty. A utilização combinada de várias fontes de evidências entrevistas, documentos e observação - possibilitou o confronto das informações obtidas com base em cada fonte, conferindo maior confiabilidade aos resultados da pesquisa (GREENWOOD, 1973; EISENHARDT, 1989; YIN, 2005).

Para o tratamento dos dados obtidos, utilizou-se o método de análise de conteúdo. Essa metodologia consiste no uso de técnicas de sistematização, interpretação e descrição do conteúdo das informações, a fim de compreender melhor o discurso e extrair os detalhes mais importantes. Com isso, foi possível examinar as várias dimensões dos relatos dos entrevistados e construir inferências com base neles (GODOY, 1995; BAUER; GASKELL, 2002). Para facilitar essa etapa, criaram-se categorias de análise, com base na literatura, revisadas à luz das evidências da pesquisa (EISENHARDT, 1989).

Por fim, é importante ressaltar também que, num primeiro momento, examinaram-se as informações obtidas nos documentos secundários sobre a história de Paraty e, posteriormente, fez-se a análise dos dados coletados por meio das entrevistas. 


\title{
4. Descrição e análise dos dados
}

\author{
4.1 O CASO ESTUdADO: O CONTEXTO HISTÓRICO E OS PROCESSOS DE RECONVERSÃO DE FUNÇÕES \\ ECONÔMICAS DE PARATY (RJ)
}

A caracterização histórica que se segue foi feita com base nos documentos bibliográficos sobre Paraty. Analisando a evolução de Paraty, contatou-se que seus processos de reconversão podem ser delimitados em três períodos: (i) povoamento e urbanização de Paraty: entreposto comercial e rota de acesso ao ouro nas Minas (até o século XVIII); (ii) declínio e esquecimento de Paraty: abertura de novos caminhos por terra e ferroviário para as Minas (entre o século XVIII até o século XX); (iii) ressurgimento e início do ciclo do turismo cultural: abertura da estrada Rio-Santos (a partir da segunda metade do século XX).

A data de fundação de Paraty e os atores responsáveis por seu descobrimento divergem de historiador para historiador. Alguns estudiosos apontam que, antes da colonização portuguesa no Brasil, o local referente ao atual município de Paraty já era ocupado pelos índios guaianás (MELLO, 1994). O descobrimento da região, entretanto, não deve ser confundido com o início de seu povoamento por portugueses. Ela começa a ser povoada somente por volta de 1530, quando a expedição de Martim Afonso de Sousa vem ao Brasil em busca do caminho para as Minas. Assim, ele estabelece o povoado de São Vicente e dá porções de terras para que portugueses se instalem no Brasil. Esses moradores, aos poucos, vãose dispersando pelo litoral e criando pequenos povoados (GURGEL; AMARAL, 1973; JORNAL DE PARATY, 2011).

Além dessas versões, há estudos que informam que o descobrimento de Paraty se deu em 1606, quando o sistema de Capitanias Hereditárias foi implantado no País por Portugal, com o intuito de proteger a região para a exploração exclusiva de seus recursos. Com a criação da capitania de São Vicente, a baía da Ilha Grande, incluindo Paraty, acaba tornando-se o principal caminho de acesso ao interior do País (BARROS, 2003).

De todo modo, pode-se afirmar que, no final do século XVI, já havia um crescente grupo de "paratienses" estabelecidos na região. O desenvolvimento de Paraty deveu-se à posição estratégica e a seu porto marítimo que dava acesso aos navegadores e que chegou a ser o segundo mais importante do País (HISTÓRIA, 2011; IAHP, 2011).

Nesse contexto, Paraty torna-se o ponto de entrada e passagem para os que buscavam o interior do País à procura de ouro e um importante entreposto comercial onde entrava e saía a maior parte das mercadorias trazidas de Portugal e/ou extraídas do Brasil (HISTÓRIA, 2011; JORNAL DE PARATY, 2011). Assim, foi-se construindo, nos caminhos que davam 
acesso a Minas, uma estrutura (mercadorias, produtos, serviços) para dar suporte à atividade extrativa. Tal desenvolvimento contribuiu também para a expansão do número de vilas na região (SOUZA, 2003; IAHP, 2011).

Com o desenvolvimento da região de Paraty, os habitantes do povoado começam a dar-se conta de sua importância para a baía de Ilha Grande. Assim, inicia-se, em 1660, uma revolta popular exigindo a separação entre Paraty e Angra dos Reis, o que não foi bem visto pelo povoado de Angra. Após sete anos de luta, Paraty consegue separar-se de Ilha Grande, em 1667, sendo reconhecida pelo nome de Vila de Nossa Senhora dos Remédios de Paraty. Em outubro do mesmo ano, instalou-se a primeira Câmara Municipal no local e nomearam-se as autoridades da nova vila (HISTÓRIA, 2011).

Com a criação dessa estrutura, Paraty torna-se caminho obrigatório para o escoamento do ouro das Minas, a partir de 1693. Esse trajeto ficou conhecido como o "Caminho Velho do Ouro" (MELLO, 1994; BARROS, 2003). A descoberta crescente de ouro em Minas Gerais, no início do século XVIII, ampliou o fluxo de pessoas transitando na região. Para evitar o contrabando, criaram-se, em 1703, Casas de Registro do Ouro em Paraty e extinguiram-se as outras casas existentes no País, à exceção da de Santos (GURGEL; AMARAL, 1973).

A atividade extrativa do ouro foi responsável, por quase dois séculos, do desenvolvimento em Paraty. Construíram-se casarões com excelentes técnicas arquitetônicas, estabeleceram-se igrejas e abriram-se novas ruas e calçadas com pedras irregulares, características do atual centro histórico (JORNAL DE PARATY, 2011; MELLO, 2011). Além disso, o comércio tornou-se cada vez mais intenso: houve um incremento no cultivo de cana-de-açúcar e na produção de aguardente, seguido da produção cafeeira. Em 1844, Paraty foi elevada à categoria de cidade (TCE-RJ, 2009).

Entretanto, após décadas de progresso, Paraty entrou num período de declínio em razão de um conjunto de fatores. Uma das causas foi a abertura, em 1700, de um caminho mais curto e protegido para as Minas, pois o trajeto até então utilizado incluía um trecho marítimo do Rio de Janeiro para Paraty que era considerado perigoso. Com isso, houve uma mudança no trajeto que as pessoas utilizavam para alcançar Minas, gerando um esvaziamento do trecho que incluía Paraty (LENZIARDI, 2011).

Outro fator que contribuiu para a decadência da cidade de Paraty foi a abertura, em 1870, de um novo caminho - dessa vez, ferroviário - entre Rio e São Paulo, através do Vale do Paraíba, fazendo com que os caminhos por terra perdessem a função. Assim, a instalação da estrada de ferro reduziu o movimento do porto e acabou por isolar Paraty. Finalmente, a abolição da escravatura, em 1888, gerou um êxodo da mão de obra local e de parte significativa da população da cidade (JORNAL DE PARATY, 2011).

Esse período de esquecimento perdurou até a segunda metade do século $X X$, ficando 
Paraty abandonada e acessível somente por mar (LENZIARDI, 2011). O acesso a Paraty somente foi reaberto por terra em 1953, por meio da Estrada Paraty (RJ)-Cunha (SP), que tem o piso sobre parte do antigo "Caminho do Ouro". Embora tal estrada possa ter contribuído para o início de um turismo antes desconhecido pelos habitantes da cidade, o trecho era bastante precário e só comportava movimento quando não chovia, não solucionando o isolamento de Paraty (HISTÓRIA, 2011; IAHP, 2011).

Paraty somente veio a ser redescoberta a partir de 1976, com a abertura da Rodovia Rio-Santos (BR-101) que colocou a região, no eixo rodoviário RJ-SP. Com isso, Paraty tornou-se amplamente acessível, impulsionando a vocação turística que a região já apresentava por seu conjunto paisagístico/arquitetônico e suas belezas naturais. Inicia-se, assim, um novo ciclo em que a cidade deixa de ser um lugar de temporadas e passa a ser uma opção de turismo o ano inteiro (HISTÓRIA, 2011; JORNAL DE PARATY, 2011).

Com o aumento do fluxo turístico em Paraty, surgem novas formas de penetração de capital, de bens e serviços antes inexistentes, passando a estimular o desenvolvimento socioeconômico da região. Os caiçaras que, anteriormente, habitavam o Centro Histórico de Paraty não resistiram ao elevado preço oferecido para a aquisição de seus imóveis e venderam suas casas, sendo obrigados a migrarem para bairros periféricos. Assim, a parte histórica foi totalmente ocupada por lojas, restaurantes e pousadas (IAHP, 2011).

Desde essa época, o turismo é uma das principais atividades econômicas de Paraty e mobiliza boa parte da comunidade. A cidade dispõe de uma diversidade de atrativos turísticos, como o marítimo, o ecológico e o artístico-cultural (TCE-RJ, 2009).

Do ponto de vista cultural, Paraty guarda importantes monumentos históricos e arquitetônicos dos séculos XVIII e XIX. O Centro Histórico de Paraty, por exemplo, revela um conjunto arquitetônico característico da época colonial (LENZIARDI, 2011). Nesse contexto, vale salientar que a cidade foi considerada Patrimônio Estadual (1945), tombada pelo Patrimônio Histórico e Artístico Nacional (1958) e transformada em Monumento Nacional (1966). Atualmente, o governo está solicitando à UNESCO a candidatura da cidade a Patrimônio da Humanidade (HISTÓRIA, 2011; TCE-RJ, 2009).

O calendário de eventos da cidade é repleto de atrações. Todavia algumas festas merecem destaque, como a Festa Literária Internacional de Paraty (FLIP) e o Festival Internacional de Jazz. A FLIP, especificamente, é realizada desde 2003 e consiste no encontro de autores renomados para discutirem-se obras literárias, além da realização de shows, exposições e exibição de filmes. É um dos principais festivais literários do mundo e traz um fluxo significativo de pessoas a Paraty (FLIP, 2011).

Ao mesmo tempo em que a expansão do turismo contribuiu para o desenvolvimento de Paraty, também gerou impactos negativos na região. Um desses efeitos foi o deslocamento 
da população nativa do Centro Histórico para a periferia, como citado anteriormente. Nesse processo, o modo de vida tradicional e as manifestações artísticas da comunidade foram prejudicados. Além disso, o fluxo turístico gerou um impacto ambiental na região (IAHP, 2011). Nesses termos, o Poder Público, os empresários e a comunidade de Paraty deveriam considerar os impactos do turismo na cidade como importante item de discussão (FREITAG, 2003).

\subsection{INTER-RELAÇÃO E CAPITAIS MOBILIZADOS POR DIFERENTES TIPOS DE EMPREENDEDORES EM}

PARATY: OS TRADICIONAIS, OS MODERNOS E OS PÓS-MODERNOS

Para complementar a análise feita com base nos documentos secundários, esta seção apresenta os achados com base em entrevistas realizadas em Paraty. Após análise, observou-se que alguns acontecimentos foram decisivos nas transformações econômicas vivenciadas pela cidade.

As entrevistas confirmaram que o ciclo de turismo em Paraty se iniciou efetivamente após a abertura dos acessos à cidade, sobretudo da estrada Rio-Santos. Entretanto, a atividade turística somente foi fomentada em função de algumas características peculiares da cidade que chamam a atenção dos visitantes. Um desses traços é o patrimônio arquitetônico e histórico, preservado em decorrência, paradoxalmente, do período de esquecimento vivenciado pela cidade e do tombamento dos ativos pelo Patrimônio Histórico. Assim, casas, igrejas e ruas foram mantidas intactas, dando um caráter colonial à cidade (Entrevista 9).

Além da preservação do patrimônio material da cidade, as entrevistas indicam que Paraty carrega um traço cultural e artístico muito forte que constitui, atualmente, a base de seu turismo cultural. Isso porque a cidade foi influenciada por pessoas com diferentes estilos culturais e dos mais diversos países do mundo, já que foi a principal porta de entrada no Brasil para os que buscavam o ouro nas Minas Gerais.

Além dessa influência estrangeira, Paraty era muito frequentada por artistas brasileiros (poetas, artistas plásticos, de televisão) que buscavam um lugar tranquilo, antes mesmo da abertura da Rodovia Rio-Santos (Entrevistas 1, 3, 4, 8, 10, 12, 13, 20). Assim, foram deixando também uma marca cultural muito evidente na cidade, conforme corrobora o relato abaixo.

Antigamente quem vinha pra cá era poeta, cineasta, as pessoas vinham pra cá em busca de sossego e em busca de inspiração.

Porque aqui era uma cidade que inspirava as pessoas. Paraty era poética linda e pura (Entrevista 10). 
Entre as pessoas que vinham a Paraty, os paulistas tiveram uma influência importante no desenvolvimento da cidade. Com a abertura da estrada Paraty-Cunha, muitos deles adquiriram casas no Centro Histórico e integraram-se no cotidiano da comunidade. Dessa forma, para uma cidade que estava esquecida, a chegada dos paulistas alavancou economicamente a região, não somente pela aquisição de imóveis, mas também pela necessidade de estabelecerem-se comércios variados na localidade. Além disso, o perfil desse público - instruído, culto e com elevado poder aquisitivo - contribuiu para o fortalecimento do caráter cultural de Paraty (Entrevistas 1, 4, 5, 10, 12).

Entretanto, os processos de transformação econômica de Paraty são marcados por contradições e conflitos entre atores/instituições com diferentes interesses que impactam a dinâmica de desenvolvimento da cidade e, especificamente, os tipos de empreendimentos que ali se instalam. Uma contradição presente nas entrevistas está relacionada com o perfil artístico-cultural da cidade e com o aumento do "turismo de massa" no local. Diversos entrevistados sugerem que, em função da vocação cultural de Paraty, o perfil do turista "adequado" à cidade é o de quem tem uma bagagem cultural, que aprecia arte e com condições financeiras suficientes para usufruir de pousadas e restaurantes que, em sua maioria, têm um preço elevado (Entrevistas 1, 5, 6, 8, 11, 12, 13, 14, 16, 18 20), conforme confirmam os relatos abaixo.

Paraty não é uma cidade para qualquer um vir. Nós gostamos de todos os públicos, mas quem vem aqui são pessoas já formadas, profissionais liberais, gente de muito bom gosto. Que é esse o turista que compreende o patrimônio histórico, o calçamento, as galerias de arte, o patrimônio cultural (Entrevista 20).

Entretanto, percebe-se, nos últimos anos, a alteração do perfil do público que tem visitado Paraty. Ou seja, houve um aumento no fluxo de turistas que não valorizam o patrimônio artístico-cultural da cidade e que não têm aproveitado a infraestrutura que lhes é oferecida, prejudicando o fluxo econômico local (Entrevistas 1, 4, 5, 6, 7, 8, 11, 20).

Vale salientar, entretanto, que o perfil do público que frequenta Paraty varia, dependendo do evento promovido na cidade. Entre os eventos, há aqueles relacionados com arte e cultura, como a FLIP, e festivais mais populares, como o Réveillon e o Carnaval. Assim, em função dos eventos, há uma delimitação do perfil do turista que visita a cidade (Entrevistas $3,5,8,9,12,19)$.

Diante do exposto, a maior parte dos entrevistados entende que a Prefeitura deveria estimular os eventos associados à arte e cultura, os quais são compatíveis com a vocação da cidade. Todavia há evidências de que a Prefeitura promove festivais de diversas naturezas e 
para atender a todos os tipos de público, o que, do ponto de vista de alguns entrevistados, prejudica a imagem e o turismo cultural de Paraty. Portanto, uma das dicotomias que se percebe, com base nos dados analisados, é entre o perfil cultural-artístico de Paraty e o aumento do "turismo de massa" na cidade (Entrevista 12).

Outras contradições no processo de reconversão de funções econômicas de Paraty decorreram do ciclo do turismo. Uma delas foi o deslocamento da população nativa da cidade que morava no Centro Histórico para a periferia (Centro Histórico x periferia), conforme discutido anteriormente. Assim, o Centro Histórico de Paraty passou a diferenciar-se em relação a outras áreas da cidade, tornando-se um ponto privilegiado para negócios e concentrando a maior parte dos estabelecimentos comerciais voltados para atender os turistas: "A atração da cidade fica no Centro Histórico, como se fosse um shopping a céu aberto." (Entrevistas 6, 9, 10).

Além disso, com a abertura de empreendimentos na cidade, parte da população nativa passou a trabalhar em restaurantes e pousadas, mudando o modo de vida anterior, baseado na pesca e na agricultura para subsistência. Se, por um lado, isso gerou uma renda para a comunidade, por outro, pode ter significado uma perda de seus costumes e tradições (Entrevistas 6, 9, 10).

Então, enquanto o ciclo do turismo foi importante por trazer desenvolvimento econômico para Paraty, também foi perverso por causar o deslocamento da população nativa de seu local de origem.

Há de ressaltar-se, entretanto, que, embora tenha ocorrido essa fragilização cultural, há indícios de que não existe "preconceito" da população nativa em relação àqueles que foram morar em Paraty posteriormente (Entrevistas 8, 12, 15, 19). Isso posto, entende-se que as pessoas podem trazer uma experiência importante para a cidade ou desenvolver algum negócio que pode torná-la mais atrativa.

A gente paratiense não tem aquilo "os de dentro e os de fora". Não há preconceito. Desde que a pessoa venha a Paraty e comece a produzir, trabalhar e participar da cidade, é muito bemvinda

(Entrevista 12).

Além disso, as pessoas não nascidas em Paraty criaram uma ligação com a cidade e integraram-se no cotidiano do local, reduzindo a possibilidade de discriminação entre "nativos" e "estrangeiros" (Entrevistas 3, 4, 5, 12).

As contradições expostas e o processo de reconversão de funções econômicas de Paraty influenciam a forma de atuação dos diversos atores sociais (Poder Público, associações e empreendedores) presentes no local e o modo como se relacionam. Portanto, feita a análise dessa dinâmica, foi necessário também compreender as características e as 
formas de atuação dos atores.

Com relação à atuação da Prefeitura de Paraty, há evidências de que a forma de gestão ainda é tradicional e personalista. Os entrevistados apontam que há um processo de nepotismo na Prefeitura, isto é, muitas pessoas que ocupam cargos públicos importantes têm ligação familiar com o prefeito (Entrevistas 1, 2, 4, 5, 10, 15, 19, 20, 21). Além disso, parte importante da população de Paraty trabalha ou presta serviços à Prefeitura e, portanto, há uma dependência da população em relação ao Poder Público. Assim, qualquer reivindicação contra a Prefeitura não obtém adesão popular na cidade.

Outro fator que também tende a limitar a atuação do Poder Público em Paraty é a falta de profissionais especializados à disposição da Prefeitura. A execução de projetos mais complexos depende de mão de obra externa. Uma das causas disso é o ensino superior na cidade que ainda é muito precário (Entrevistas 10, 18).

Com relação à atuação da Prefeitura para apoiar o turismo, há indícios de que sua preocupação já foi maior com essa atividade. Os entrevistados justificam que a Prefeitura não depende mais da renda do turismo como ocorria antigamente, pois, há alguns anos, a cidade vem recebendo royalties do petróleo, um recurso financeiro significativo que elevou o orçamento público. Com isso, o turismo deixou de ser a principal fonte de receita do município e, consequentemente, a Prefeitura tem direcionado menos esforços para esse setor (Entrevistas 4, 10, 17, 18, 19).

Porque em seis anos a cidade saiu de trinta milhões de receita anual para duzentos milhões por causa dos royalties do petróleo. Então antigamente toda a direção que se tomava no município era voltada exclusivamente para o turismo porque a cidade vivia do turismo. Hoje não, o município, o órgão público, vive dos royalties

(Entrevista 19)

Além da Prefeitura, há outras instâncias públicas que influenciam a dinâmica de reconversão de funções econômicas de Paraty, como os órgãos de proteção ambiental, especialmente nesse caso em que todo o município é tombado pelos Patrimônios Estadual e Municipal. Com isso, há uma série de leis que regulam as intervenções que são feitas na cidade. Por um lado, há entrevistados que atribuem a preservação do patrimônio de Paraty à atuação desses órgãos (Entrevista 9). Entretanto a maior parte entende que a intervenção dessas entidades é ineficiente por gerar atrasos na aprovação de projetos e por excesso de burocracia, além de inibir o desenvolvimento local ao embargarem obras que poderiam trazer benefícios para a cidade (Entrevistas 3, 10, 15, 17, 30, 21).

Além do Poder Público, as transformações de uma cidade podem ser reforçadas pela 
atuação de associações que se articulam em defesa dos interesses locais. Entretanto há indícios de que a comunidade e os empresários de Paraty têm dificuldades ou não têm hábito de associarem-se e estabelecerem parcerias. Além disso, entendem que as ações em benefício da cidade são de competência exclusiva da Prefeitura, revelando certa dependência do Poder Público (Entrevistas 3, 4, 5, 7, 11, 12, 14, 18, 19, 20).

Ainda assim, alguns entrevistados citam algumas associações importantes em Paraty, entre elas o Convention \& Visitors Bureau: entidade formada, especialmente por empresários que se articulam em prol do turismo na cidade. Não obstante, há indícios de que a adesão a tal associação é baixa (Entrevista 4).

Além do Poder Público e das associações, o empresariado de Paraty também tem uma influência no desenvolvimento da cidade. Para a análise dos tipos de empreendimentos de Paraty, utilizaram-se, como referência, os estudos de Bourdieu (2010; 2009a; 2009b) e de Santanna, Nelson e Oliveira (2011) que identificaram tipos de empreendedores na cidade de Tiradentes.

Com base nos dados das entrevistas, é possível identificar a presença de diferentes tipos de empreendedores em Paraty. De modo geral, vindos ou não de fora, alguns deles se preocupam com as questões que afetam Paraty como um todo, além da gestão dos próprios negócios. Por outro lado, há outros que revelam iniciativas mais isoladas e não se associam para lutar pelos interesses coletivos (Entrevistas 19, 20).

Além disso, observou-se que há dois tipos de empresários em Paraty no que tange à forma como conduzem os negócios. Por um lado, há o que tem qualificação e trabalha de forma profissional, buscando aperfeiçoar seus produtos e serviços. São indivíduos que vêm de fora com experiência em outras empresas. Por outro lado, existe o que, por ter nascido na região, não teve oportunidade de estudar e, assim, não apresenta uma visão gerencial do negócio. Com isso, tende a ser menos ativo no que se refere à realização de ações para a melhoria de seu negócio.

Em Paraty, você tem dois tipos de pessoas no comércio, você tem o empresário que é aquele que planeja o negócio dele. Vai ganhar dinheiro e vai sobreviver. E você tem aquele empresário que resolve fazer um quartinho aqui e ali, que aluga a casa dele, mas que está sempre vazio. Então, você tem esses dois tipos: tem o empreendedor que é empreendedor e tem o empreendedor que faz de conta que é

(Entrevista 8)

Com relação às categorias propostas por Santanna, Nelson e Oliveira (2011), é possível observar a presença de "empreendedores tradicionais nativos" em Paraty. São pequenos 
comerciantes e empreendedores individuais, nascidos na cidade, com discursos centrados na valorização do "nome de família". Apenas uma pequena parcela desses empreendedores localiza-se no Centro Histórico de Paraty, pois, atualmente, a maior parte dos negócios instalados na região é de pessoas de fora (Entrevistas 4, 8, 10, 12, 17).

Além disso, os empreendedores nativos têm um modo de vida simples e valorizam o fato de serem "paratienses". Embora revelem uma forte ligação com Paraty, têm uma atuação pouco expressiva em relação às questões que afetam a cidade e em relação ao crescimento de seus negócios. Em função disso, muitas vezes são rotulados de "conservadores" e "sem ambição" (Entrevistas 4, 9, 12, 19).

Tem empreendedores que nasceram aqui e vivem isso. Para eles, se a gente falar de cultura, eles vão se assustar, na verdade eles vivem aquilo sem saber que aquilo é cultura (Entrevista 12).

Assim como os nativos, os dados revelam também a presença de "empreendedores aristocratas" em Paraty (Entrevistas 1, 15, 17). São aqueles que não têm uma instrução formal, mas vivenciaram experiências em outras cidades, permitindo que seus negócios apresentem certo toque de sofisticação e de bom gosto. Esse grupo se diferencia pelo "nível cultural" e está vinculado a atributos como "cultura", "bom gosto", "estilo" e "estética".

No âmbito dos empreendedores modernos, as entrevistas demonstram a presença de "empreendedores modernos conscientes" em Paraty. São, em sua maioria, pessoas não nascidas na cidade, com qualificação formal (curso superior) e que utilizam práticas gerenciais na gestão de seus negócios, como seleção e treinamento de funcionários. Muitos deles deixaram as grandes capitais e seus empregos e foram morar em Paraty em busca de melhor qualidade de vida. Nas entrevistas, eles ressaltam que são "apaixonados" pela cidade e pelo estilo de vida que se Ihes oferece (Entrevistas 4, 9, 12, 19).

Nós viemos para fazer negócio, ter qualidade de vida e valorizar mais ainda aquilo que já existia na cidade. Todos esses eventos que foram trazidos têm uma contribuição nossa (Entrevista 4).

Além disso, esses empreendedores apresentam discursos de preocupação sobre os aspectos coletivos da cidade e os impactos negativos que o turismo traz para a região. Assim, tendem a estimular articulações entre os indivíduos em prol de ações para o desenvolvimento local, embora muitas delas não tenham obtido êxito pela baixa adesão das pessoas. Vale salientar que diversos eventos importantes em Paraty foram idealizados por esses empresários (Entrevistas 4, 9, 12, 19).

Em relação à presença de "empreendedores modernos utilitaristas" em Paraty, há divergências de opiniões. Alguns entrevistados sugerem que não existem negócios com esse 
perfil na cidade, pois os empresários têm ligação afetiva com a cidade e suas intenções, ao instalarem-se na região, extrapolam o resultado financeiro do negócio. Além disso, não há negócios de grande porte em Paraty, em função de restrições dos órgãos ambientais e pela característica do Centro Histórico da cidade que já não tem condições mais de expandir-se. Assim, é pouco provável que empresários se instalem em Paraty com a intenção de abrir grandes negócios e ganhar muito dinheiro (Entrevistas 4, 8, 9, 12, 19).

Não acredito que há aquele perfil de empreendedor que só vem com foco no lucro, sempre possui algum tipo de ligação com a cidade. Eu diria que transformar isso aqui numa sanguessuga é difícil, porque as pousadas são relativamente pequenas (Entrevista 4).

Paraty tem uma coisa interessante, felizmente também não baixou um megaempreendimento tipo aqueles hotéis que têm trezentos apartamentos como Angra tem (Entrevista 12).

Por outro lado, o Entrevistado 20 sugere que há empresários que se instalam em Paraty com o propósito exclusivo de obter retorno financeiro e não têm nenhum vínculo com a cidade, como revela o trecho: "Tem muito comércio em que o gerente é apenas um administrador local para arrecadar o dinheiro e encaminhar para os bancos de SP ou RJ".

Com relação aos "empreendedores pós-modernos", foi possível observar a presença de "vanguardistas" e de "camaleões" na cidade em estudo. A princípio, as entrevistas e as visitas in loco revelaram a existência de inúmeros ateliers de arte e lojas com produtores artísticos em Paraty, indicando a presença marcante de "empreendedores vanguardistas". Os donos desses negócios são, geralmente, indivíduos com experiências culturais adquiridas em outras cidades/países e que encontraram em Paraty, o lugar apropriado para divulgar e vender suas artes (Entrevistas 1, 4, 12). São caracterizados por atributos, como "criação", "novo", "independência", "contestação", e por "estilos de vida particulares".

A partir de 1940, há a presença de artistas plásticos em Paraty, desenhando, pintando Paraty. E, na década de 1990 em diante, há uma imensidão de artistas plásticos das mais variadas atividades, como ceramistas, escultores, pintores. Paraty tem um mercado de arte muito interessante em função do turismo cultural (Entrevista 12).

Um aspecto comum entre esses empreendedores é que todos se mostraram apreensivos com o "turismo de massa" que tem frequentado a cidade nos últimos anos e alertaram 
que é fundamental a atuação do Poder Público para atrair um público que efetivamente aprecia arte. Entretanto vale salientar que eles, geralmente, não se associam para lutar por esses interesses (Entrevistas 1, 4, 6, 7, 12, 13).

É possível observar também "empreendedores camaleões" em Paraty. São pequenos comércios, geralmente de trabalhadores da cidade, que encontram, nos eventos promovidos na região, a oportunidade de ganhar dinheiro. Assim, é muito comum que abram seus negócios de forma temporária e improvisada. Usualmente, inseridos na economia informal, propõem-se a oferecer produtos e serviços a turistas sem condições financeiras para usufruir de pousadas e restaurantes sofisticados (Entrevistas 5, 9, 12, 19).

Existem aqueles que improvisam. O negócio tem começo e fim, já sabem quando começa e já sabem quando vai acabar. Isso tem aos montes. Aqueles que, na temporada, abrem creperia e fecham depois

(Entrevista 12).

Esse perfil de empreendedores, raramente, articula-se e estimula iniciativas visando ao interesse coletivo e local.

A análise feita acima revela, portanto, a presença de diferentes tipos de empreendedores (tradicionais, modernos e pós-modernos) em Paraty, os quais se diferenciam pelas características, pela forma como fazem a gestão de seus negócios e como lidam com as questões coletivas da cidade, convergentes com os achados de Santanna, Nelson e Oliveira (2011).

\section{5. . Considerações finais}

A experiência de Paraty com o processo de reconversão de funções econômicas de cidades e com os diferentes tipos de atores atuantes no local (Poder Público, associações, empreendedores) revelou elementos importantes sobre os fenômenos analisados. Um ponto que merece ser ressaltado é que os diferentes tipos de empreendedores não atuam em um vácuo social, nem são independentes uns dos outros, especialmente em contextos que compartilham do mesmo patrimônio histórico, cultural e natural. Eles fazem parte de uma interação social, marcada por conflitos e alianças e pela disputa por capitais, espaço e poder, dados convergentes com as pesquisas de Bourdieu (2010, 2009a, 2009b, 1990).

Os achados do estudo em Paraty corroboram também evidências da pesquisa realizada por Santana, Nelson e Oliveira (2011) na cidade de Tiradentes (MG). Assim como na cidade de Minas Gerais, em Paraty, observou-se que alguns tipos de empreendedores (tradicionais, modernos e pós-modernos), cada qual com atributos peculiares, mobilizam diferen- 
tes capitais e estabelecem conflitos e alianças para a obtenção de espaço, recurso e poder. Constatou-se também que eles têm objetivos distintos quanto ao modelo de gestão de seus negócios e, principalmente, quanto à forma de atuação para o desenvolvimento da cidade, produzindo impactos distintos sobre a dinâmica econômico-social do local.

Os empreendedores tradicionais nativos (paratienses), embora sejam conservadores e não se associem para lutar pelas questões coletivas, têm uma ligação com a história de Paraty, uma vez que a maioria já mantinha negócios no local antes do crescimento do turismo. Os aristocratas, por sua vez, tiveram um papel fundamental no desenvolvimento da cidade, pois zelaram pelo conjunto arquitetônico histórico. Além disso, reforçaram valores de cultura, memória histórica e respeito ao local no seio desse processo.

Os empreendedores modernos conscientes também tiveram uma influência importante nesse processo, ao difundirem valores de responsabilidade social e ao buscarem associar-se em prol das questões coletivas da cidade. Já a presença de empreendedores modernos utilitaristas na cidade de Paraty é uma questão que ainda merece investigação, tendo em vista as opiniões divergentes dos entrevistados. Se, por um lado, alguns sugerem que não existem negócios com esse perfil em Paraty, pois os empresários, geralmente, têm uma ligação afetiva com a cidade, por outro, há respondentes sugerindo que existem empresários que se instalam em Paraty com o propósito exclusivo de obter retorno financeiro e não têm qualquer vínculo com a cidade.

Finalmente, os empreendedores pós-modernos vanguardistas atuaram de forma arrojada ao identificarem a cidade como digna de atenção por meio de suas características estéticas e artísticas. Mesmo os empreendedores camaleões contribuíram ao permitir que um público de menor renda possa visitar Paraty e, de alguma forma, ter acesso a suas belezas e riquezas. É patente que, ao mesmo tempo em que cada tipo de empreendedor tem seu papel, seus objetivos e suas influências coexistem em um estado de tensão perpétua, expostos ao risco de um desequilíbrio potencialmente desastroso.

Entende-se que a literatura sobre empreendedorismo ainda não está atenta à dinâmica de coexistência entre tipos de empreendedores distintos. Entender que o empreendedor se insere num contexto social em que outros empreendedores têm papéis diferenciados e conflituosos não é a única contribuição deste estudo. Constatou-se, também, que o empreendedor depende do entorno de formas ainda não explicitadas na literatura.

Finalmente, o estudo permitiu que se investigassem relações entre os tipos de empreendedores e as dinâmicas sociais e econômicas, observados durante o processo de reconversão de funções econômicas de Paraty, o qual, em um período de tempo relativamente curto, permitiu à cidade superar a condição de abandono para configurar-se como um dos principais destinos turísticos do Brasil. 


\section{Referências}

BAKER, T.; NELSON, R. Creating something from nothing: Resource construction through entrepreneurial bricolage. Administrative Science Quarterly, vol. 50, p. 329-366, 2005.

BALASTRERI, A. Turismo e territorialidades plurais -- lógicas excludentes ou solidariedade organizacional. In: GERAIGES DE LEMOS, Amalia Inés; ARROYO, Mónica; SILVEIRA, María Laura (orgs.). América Latina: cidade, campo e turismo. Buenos Aires: Consejo Latinoamericano de Ciencias Sociales - CALCSO; São Paulo: Universidade de São Paulo - USP 2006.

BARROS, A. M. A importância da história de Paraty. Disponível em: <http://www. uff.br/patrimoniosdeparaty/fjustificativa.htm>. 2003. Acesso em julho/2011

BAUER, Martin W.; GASKELL, George. Pesquisa ualitativa com texto, imagem e som: um manual prático. 2. ed. Petrópolis: Vozes, 2002.

BENTLEY, Gill. Fitting the piece in the jigsaw puzzle? The governance of local economic development policy and regeneration in Birmingham. Local Economy, vol. 20, n.o 2, p. 238-243, maio 2005.

BONNEWITZ, P. Primeiras lições sobre a sociologia de Pierre Bourdieu. Petrópolis: Vozes, 2005.

BOURDIEU, P. Coisas ditas. São Paulo: Brasiliense, 1990.

A economia das trocas simbólicas. São Paulo: Perspectiva, 2009a. . O poder simbólico. Rio de Janeiro: Bertrand Brasil, 2010.

Razões práticas: sobre a teoria da ação. Campinas: Papirus, 1996.

O senso prático. Petrópolis: Vozes, 2009 b.

; ORTIZ, Renato. Pierre Bourdieu: sociologia. 2. ed. São Paulo:Ática , 1994.

CÂMARA MUNICIPAL DE PARATY. História da Cidade. Disponível em: <http:// www.paraty.rj.gov.br/camaraparaty/cultura.php?SID>. Acesso em: jun. 2011.

CASTELLS, Manuel; JORDI Borja. La ciudad multicultural. La Factoria, n.o 2, [s.I.], 1997.

COOPER, A.; RAMACHANDRAN, M.; SCHOORMAN, D. Time allocation patterns of craftsmen and administrative entrepreneurs: Implications for financial performance. Entrepreneurship: Theory \& Practice, vol. 22, n.o 2, p. 123-136, 1997. 
EISENHARDT, Kathleen M. Building theories from case study research. Standford

University. Academy of Management Review, Standford, vol. 14, n.o 4, 1989.

FESTA LITERÁRIA INTERNACIONAL DE PARATY. Disponível em: <http://www.flip. org.br/institucional.php>. Acesso em: 10 jan. 2011.

FISCHER, T. Gestão contemporânea, cidades estratégicas: aprendendo com fragmentos e reconfigurações do local. In: (org.). Gestão contemporânea: cidades estratégicas e organizações locais. Rio de Janeiro: FGV, 1996.

FREITAG, B. A revitalização dos centros históricos das cidades brasileiras. Revista do Patrimônio Histórico e Artístico Nacional, Brasília, UnB , 2003.

GARUD, R.; KARNOE, P. Bricolage versus breakthrough: distributed and embedded agency in technology entrepreneurship. Research Policy, vol. 32, n.o 2, p. 277-300, 2003.

GODOY, Arilda Schmidt. Introdução à tpesquisa qualitativa e suas possibilidades. Revista de Administração de Empresas, São Paulo, SP, vol. 35, n.o 2 , p. 57-63, mar./abr. 1995.

GREENWOOD, Ernest. Métodos principales de investigación Social empírica. In_. Metodología de la investigación social. Buenos Aires: Paidos, 1973, cap. 6, p. 106-126.

GURGEL, Heitor; AMARAL, Edelweiss Campos do. Paraty, caminho do ouro: subsídios para a história do estado do Rio. Rio de Janeiro: São José, 1973.

HARVEY, David. Condição pós-moderna. 6. ed. São Paulo: Loyola, 1996.

HISTÓRIA. Paraty: cidade Histórica, monumento nacional. Disponível em: <http:// www.paraty.com.br/entrepos.htm>. Acesso em: jun. 2011.

INSTITUTO BRASILEIRO DE GEOGRAFIA E ESTATÍSTICA (IBGE). Cidades. Disponível em: http://www.ibge.gov.br/cidadesat/topwindow.htm?1. Acesso em: maio 2011.

INSTITUTO HISTÓRICO E ARTÍSTICO DE PARATY (IAHP). A importância da história de Paraty. Disponível em: <http://www.uff.br/patrimoniosdeparaty/fjustificativa.htm>. Acesso em: jun. 2011.

JORNAL DE PARATY. História da cidade de Paraty. Disponível em: <http://www. jornaldeparaty.com.br/component/content/article/45-paraty/50-historia-da-cidade-de-paraty.html>. Acesso em: jun. 2011.

LENZIARDI, Raquel. A responsabilidade social corporativa e o desenvolvimento sustentável em meios de hospedagem de Paraty: uma análise exploratória. Rio de Janeiro: FGV, 2011. 129 páginas. Dissertação(Mestrado) - Administração, Fundação Getulio Vargas, Rio de Janeiro, 2011.

LEVI-STRAUSS, C. The savage mind. Chicago: The University of Chicago Press, 1966.

LUCHIARI, M. T. D. P. A reinvenção do patrimônio arquitetônico no consumo das cidadesIn: GEOUSP -- Espaço e Tempo, São Paulo, SP, n.o 17, 2005. 
MELLO, Diuner José. Paraty - notas históricas. Instituto Histórico e Artístico de Paraty, 1994.

MISOCZKY, Maria Ceci A. Implicações do uso das formulações sobre campo de poder e ação de Bourdieu nos estudos organizacionais. Revista de Administração Contemporânea ed. especial, p. 9-30, 2003.

PARATY CONVENTION \& VISITORS BUREAU. Disponível em: <http://www.paratycvb.com.br/site/>. Acesso em: abr. 2011.

PECl, Alketa. Estrutura e ação nas organizações: algumas perspectivas sociológicas.

Revista de Administração de Empresas, vol . 43, n.ำ mar. 2003.

RAFFESTIN, C. Por uma geografia do poder. São Paulo: Ática, 1993.

SANTANNA, Anderson de Souza; NELSON, Reed Elliot; OLIVEIRA, Fatima Bayma. Empreendedorismo e o desenvolvimento do turismo na cidade de Tiradentes. Revista Acadêmica Observatório de Inovação do Turismo, FGV/- Escola Brasileira de Administração Pública e de Empresas, vol.6, . N. ${ }^{\circ} 1,2011$.

SMITH, A. The entrepreneur and his firm: the relationship between type of man and type of company. East Lansing, MI: Michigan State University, 1967.

SOUZA, Marcelo Lopes. ABC do desenvolvimento urbano. Rio de Janeiro: Bertrand Brasil, 2003.

SOY, Susan K. The case study as a research method. University of Texas. Disponível em: <http://www.gslis.utexas.edu/ ssoy/usesusers/I391d1b.htm>. [Acesso em:]

TEIXEIRA, Juliana Cristina. Fatores considerados para escolha de parceiros de pesquisa: uma proposta teórico-metodológica para estudos em redes colaborativas de pesquisa por meio dos capitais simbólicos de Pierre Bourdieu. In: ENCONTRO DA ANPAD, 34, 2010, Rio de Janeiro. Anais... Rio de Janeiro: ANPAD, set. 2010.

THIRY-CHERQUES, Hermano Roberto. Pierre Bourdieu: a teoria na prática. Revista de Administração Pública, Rio de Janeiro, vol. 40, n.o 1, p. 27-55, jan./fev. 2006.

TRIBUNAL DE CONTAS DO ESTADO DO RJ. Estudos socioeconômicos dos municípios do estado do Rio de Janeiro. Secretaria Geral de Planejamento. Rio de Janeiro, 2009.

YIN, Robert K. Estudo de caso: planejamento e métodos. 3. ed. Porto Alegre: Bookman, 2005. 